\title{
N8 $7-29434$
}

Transonic Rotor Flow-Measurement Technique Using Holographic Interferometry

John K. Kittleson* and Yung H. Yu*

U.S. Army Research and Technology Laboratories - AVSCOM

NASA Ames Research Center, Moffett Field, California

\section{Abstract}

Holographic interferometry is used to record interferograms of the flow near a hovering transonic rotor blade. A pulsed ruby laser recorded 40 interferograms with a 2-ft-diam view field near the model rotor-blade tip operating at a tip Mach number of 0.90 . This paper presents the experimental procedure and example interferograms recorded in the rotor's tip-path-plane. In addition, a method currently being pursued to obtain quantitative flow information using computer-assisted tomography (CAT) with the holographic interferogram data, is outlined.

*Research Engineers. 
POE PAE IS
DOR QUALITY WOA QUALIY

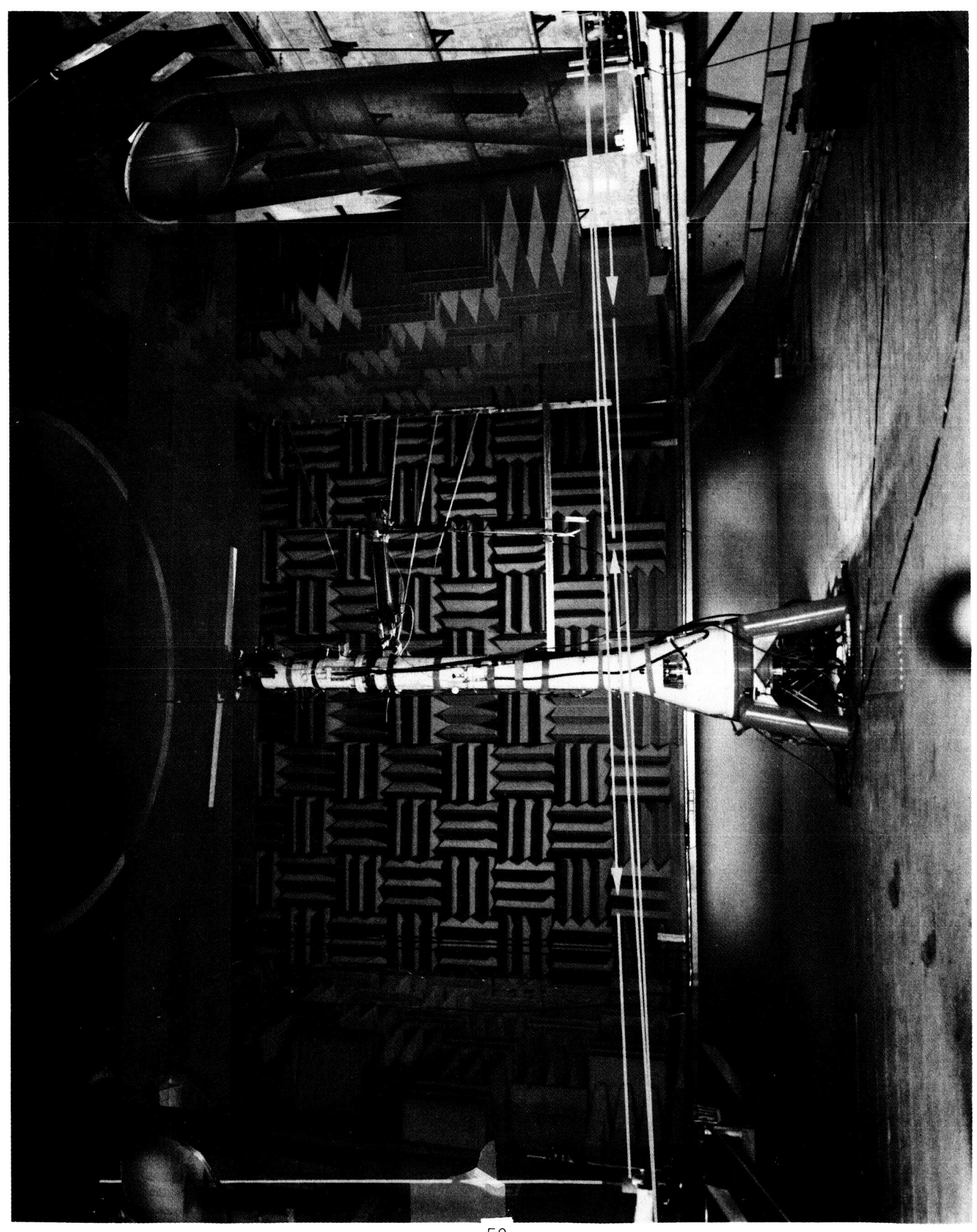




\section{INTERFEROGRAMS AT VARIOUS AZIMUTHAL ANGLES}

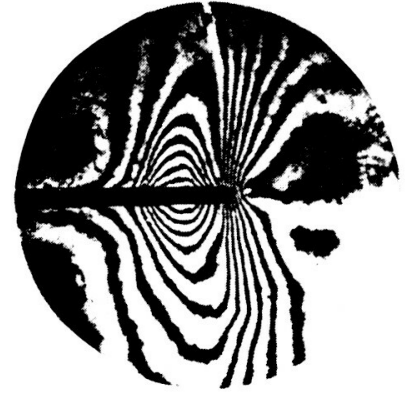

$\theta=20^{\circ}$

(a)
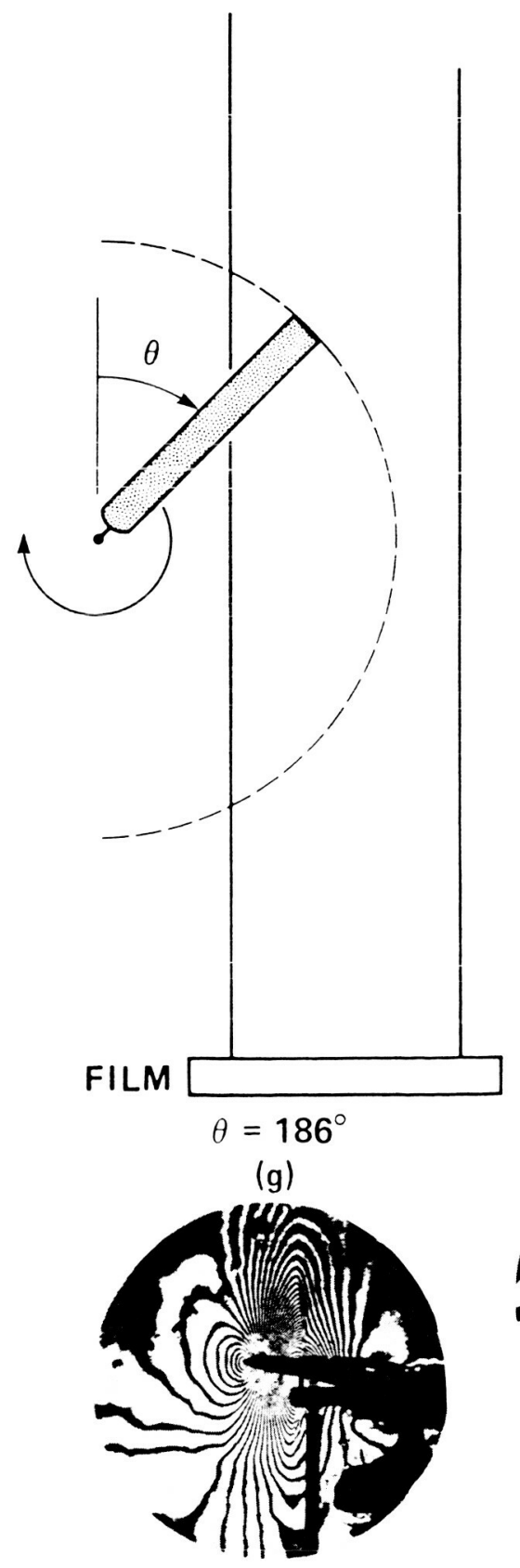

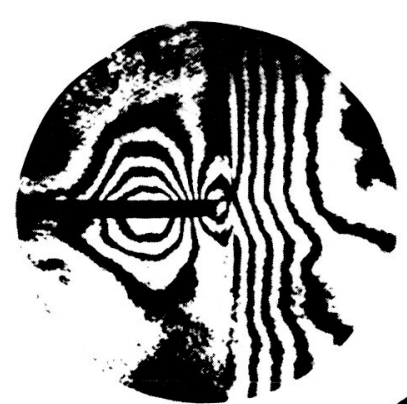

$\theta=30^{\circ}$

(b)

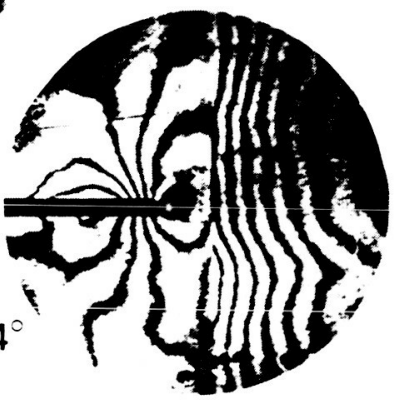

(c)

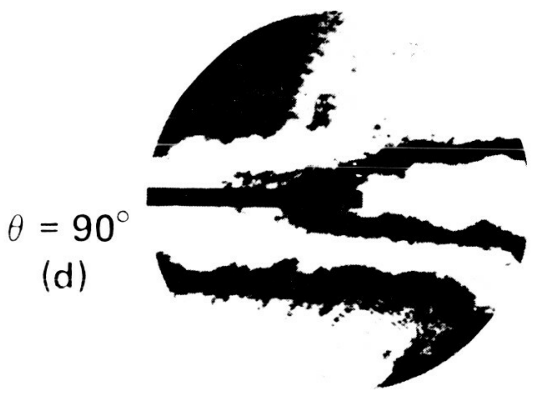

$\theta=180^{\circ}$

(f)
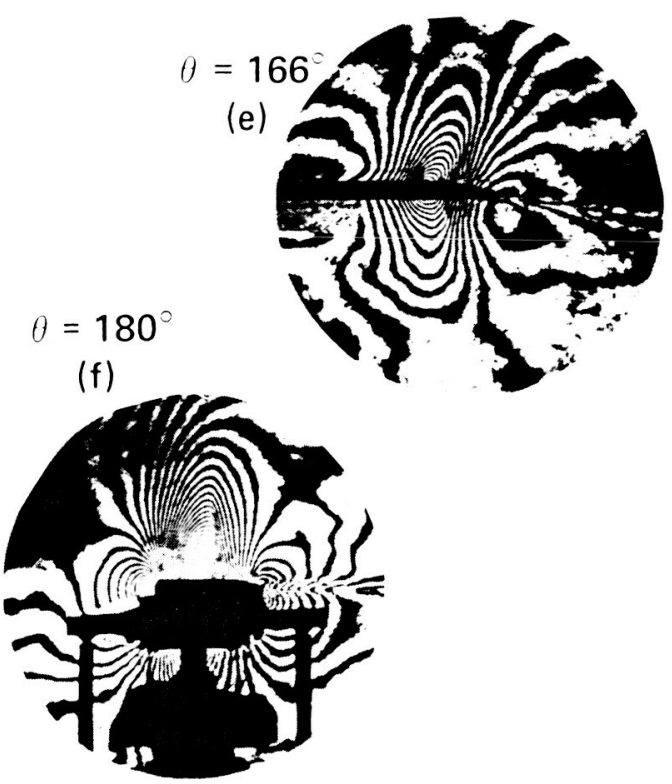